\title{
Physiological Effects of Wearing N95 Respirator on Medical Staff During Prolong Work Hours in Covid- 19 Departments
}

liran shechtman

Sheba Medical Center at Tel Hashomer: Sheba Medical Center

Gal ben-Haim

Sheba Medical Center at Tel Hashomer: Sheba Medical Center

ilan ben-zvi

Sheba Medical Center at Tel Hashomer: Sheba Medical Center

Laurence steel

Sheba Medical Center at Tel Hashomer: Sheba Medical Center

Avinoah Ironi

Sheba Medical Center at Tel Hashomer: Sheba Medical Center

ella huszti

University Health Network

Sumit Chatterji

Sheba Medical Center at Tel Hashomer: Sheba Medical Center

Liran levy ( $\sim$ liran.levy@sheba.health.gov.il)

Sheba Medical Center at Tel Hashomer: Sheba Medical Center

\section{Research Article}

Keywords: SARS CoV 2, N95, mask, respirators, physiological effects

Posted Date: May 27th, 2021

DOI: https://doi.org/10.21203/rs.3.rs-491901/v2

License: (1) (1) This work is licensed under a Creative Commons Attribution 4.0 International License.

Read Full License 


\section{Abstract}

\section{Background}

Since the emergence of coronavirus disease, health care professionals in high-risk environments are mandated to wear N95 respirators for prolonged periods. The effect of this prolonged use on cardiorespiratory variables and gas-exchange is poorly defined. The objective of the current study was to determine gas exchange abnormalities and physiological changes among healthcare workers during a 4hour emergency department (ED) shift while wearing the N95 respirator.

Methods

This was a single-center prospective observational study that consisted of medical staff working at the Sheba Medical Center ED. Physiological effects and gas exchange variables were obtained under normal breathing conditions and after 4-hour shifts while continuously wearing an N95 respirator. Comparisons of paired measurements were performed using a non-parametric Wilcoxon matched-pairs signed-rank test.

Results

Forty-one subjects were included in the study. Prolonged N95 respirator use was associated with a significant decline in plasma $\mathrm{pH}[7.35 \mathrm{mmHg}$ vs. $7.34 \mathrm{mmHg}, \mathrm{P}=0.02], \mathrm{PvO}_{2}$ [23.2 mmHg vs. $18.6 \mathrm{mmHg}$, $\mathrm{P}<0.001]$ and a concurrent increase in $\mathrm{EtCO}_{2}[32.5 \mathrm{mmHg}$ vs. $38.5 \mathrm{mmHg}, \mathrm{p}<0.0001] . \mathrm{PvCO}_{2}$ and bicarbonate levels did not differ. No significant change was observed for heart rate or oxygen saturation.

Conclusion

Using an N95 respirator for prolonged periods by healthcare professionals may provoke changes in gas exchange. The clinical significance of these changes in terms of symptoms or longer-term health status is unknown and remains to be determined.

\section{Background}

Since the emergence of serious acute respiratory syndrome coronavirus 2 (SARS CoV 2), healthcare professionals are at constant risk of contracting the virus during their daily work. The primary route of transmission of SARS CoV 2 is via aerosol droplets ${ }^{1}$, making the N95 (or FFP2) respirator an essential part of healthcare professionals' personal protective equipment (PPE). The N95/FFP2 respirator is a respiratory protective device designed to achieve a very close facial fit and filtration of greater than $95 \%$ of airborne particles greater than 0.3 microns. By comparison, the loose-fitting surgical mask used by patients and in non-high-risk medical environments creates a physical barrier to reduce the distance of spread of aerosol droplets in the immediate environment. 
The effectiveness of N95 respirators and facial masks in reducing transmission of SARS CoV 2 has been demonstrated in a number of clinical studies and meta-analysis ${ }^{2-4}$, and therefore healthcare workers internationally are mandated to wear masks during their usual daily work with patients. Prolonged mask use has been shown to be associated with various symptoms, including headache ${ }^{5}$, dizziness, facial dermatological symptoms ${ }^{6}$, as well as other interferences with occupational duties ${ }^{7}$. However, research examining potential physiologic impacts of $\mathrm{N} 95$ respirators during long work shifts of healthcare workers has been limited. The objective of the current study was to determine gas exchange abnormalities and physiological changes among healthcare workers during a 4-hour emergency department (ED) shift while wearing the $\mathrm{N} 95$ respirator.

\section{Materials And Methods}

\section{Study design and population}

This was a single-center prospective observational study approved by the Institutional Research Ethics Board. Signed informed consent was obtained from all participants. The study population comprised physicians, nurses, and medical trainees working at the Sheba Medical Center ED between September and November 2020 who were assessed during 4-hour shifts while continuously wearing an N95 respirator. Subjects with any health condition that could potentially put them at risk, such as chronic obstructive pulmonary disease, uncontrolled asthma, pulmonary hypertension, or poorly controlled heart failure, were excluded. Baseline demographic data were collected, including age, gender, medical history, and previous or active cigarette smoking.

\section{Physiologic measurements}

Subjects, at the beginning of their ED shift, were instructed to avoid any mask use for at least 15 minutes, whilst isolated away from the clinical area, to ensure baseline measurements were obtained under normal breathing. Participants were then asked to wear the N95 respirator continuously and begin their ED shift. All subjects were provided N95 respirators (Kimberly-Clark, Irving, Texas, US) for this study. Physiological measurements, including oxygen saturation and heart rate (HR), were captured at baseline and each hour up to 4 hours using an $\mathrm{O}_{2}$ saturation oximeter (Welech allyn- Vital Signs Monitor 6000, Skaneateles Falls, NY, USA). A 2CC of venous blood sample was drawn at baseline and at 4-hours (before the N95 mask was removed), using a syringe washed with heparin. The sample was immediately analyzed using a gas analyzer machine (Siemens RAPIDPoint 500, Siemens Healthcare Limited, UK). pH level, partial pressure of venous oxygen $\left(\mathrm{PvO}_{2}\right)$, partial pressure of venous carbon dioxide $\left(\mathrm{PvCO}_{2}\right)$, and bicarbonate $\left(\mathrm{HCO}_{3}\right)$ level were recorded. End-tidal carbon dioxide $\left(\mathrm{EtCO}_{2}\right)$ level was measured through non-invasive nasal prongs (Microstream CapmoLine, Philips, UK) representing the $\mathrm{EtCO}_{2}$ levels at 4-hours. After ensuring the first $\mathrm{EtCO}_{2}$ level and a typical capnography waveform, participants were asked to remove the respirator while the $\mathrm{EtCO}_{2}$ levels were continuously monitored. The lowest $\mathrm{EtCO}_{2}$ level at room air and the time required to reach it were recorded. 


\section{Statistical analysis}

Demographic characteristics were assessed as counts and percentages for categorical variables and standard measures (median and interquartile range (IQR)) for continuous variables. Comparisons of paired measurements were performed using a non-parametric Wilcoxon matched-pairs signed-rank test. All statistical analyses were performed with GraphPad Prism version 5.01 software (GraphPad Software, La Jolla, CA, USA). A p-value $<0.05$ was considered statistically significant.

\section{Power calculation}

Based on a study that examined the physiological impact of wearing an N95 mask during hemodialysis ${ }^{8}$, with a sample size of 41 pairs (of observations), we have $85 \%$ power and a level of significance of $5 \%$ (two-sided) for detecting a mean of differences of $9.0 \mathrm{mmHg}$ in $\mathrm{PaO}_{2}$ between pairs, assuming a standard deviation of the differences to be 18.5 .

\section{Results}

\section{Study cohort}

Forty-one subjects completed the study. Fifteen (36\%) were nurses, $12(30 \%)$ physicians, $9(22 \%)$ medical trainees, and $5(12 \%)$ were domestic workers. Forty (52\%) were male. Median age was 34 (interquartile range 29,37). Baseline characteristics are summarized in Table 1.

\section{Physiological variables}

Wearing an $\mathrm{N} 95$ respirator for 4-hour shift was associated with a significant decrease in $\mathrm{PH}[7.35 \mathrm{mmHg}$ $(7.32,7.37)$ at baseline vs. $7.34 \mathrm{mmHg}(7.32,7.35)$ at 4 hours, $\mathrm{P}=0.02]$ and $\mathrm{PvO}_{2}[23.2 \mathrm{mmHg}(18.2,34.5)$ at baseline vs. $18.6 \mathrm{mmHg}(14.6,23.8)$ at 4 hours, $\mathrm{P}<0.001]$. The change in $\mathrm{PCO}_{2}[49.5 \mathrm{mmHg}(44.9$, $53.1)$ at baseline vs. $50.5 \mathrm{mmHg}(47.1,56.9)$ at 4 hours, $P=0.22]$ or bicarbonate $[26.2 \mathrm{mEq} / \mathrm{L}(25.3,28.6)$ at baseline vs. $26.6 \mathrm{mEq} / \mathrm{L}(24.5,28.7)$ at 4 hours, $P=0.53)]$ did not reach statistical significance. Results are summarized in Fig. 1. There was no significant change in $\mathrm{HR}$ or oxygen saturation. Median $\mathrm{EtCO}_{2}$ under normal unmasked conditions and at 4 hours was $32.5 \mathrm{mmHg}(29.8,35)$ vs. $38.5 \mathrm{mmHg}(34,41)$, respectively $(p<0.0001)$.

\section{Discussion}

During this SARS CoV 2 pandemic, global healthcare systems have quickly realized the importance of protecting front-line workers with effective PPE. To reduce the risk of transmission to staff, N95 respirators (or the equivalent FFP2 standard) are typically worn by medical and paramedical staff in highrisk environments for prolonged periods of time without removal. The effect of this prolonged use on cardio-respiratory variables such as heart rate and gas-exchange are poorly defined. Our findings suggest 
that gas exchange is influenced by prolonged wearing of the N95 respirator, as demonstrated by a decline in plasma $\mathrm{pH}, \mathrm{PvO}_{2}$, and a concurrent increase in $\mathrm{EtCO}_{2}$. There were no significant changes in $\mathrm{PvCO}_{2}$ or bicarbonate levels. Heart rate, as well as oxygen saturation determined by pulse oximetry, were unaffected.

These findings add to previous work evaluating the impact of prolonged N95 respirator use on blood gases and physiology. Overall, available data suggest that changes in blood gases and other physiological parameters caused by N95 respirators during physical activity are small even during very heavy exercise ${ }^{9}$. In 2004, during the severe acute respiratory syndrome (SARS) outbreak in Taiwan, Kao et al. investigated the physiological impact of wearing an N95 respirator during hemodialysis on 39 patients with end-stage renal disease. $70 \%$ of participants had a reduction in the partial pressure of oxygen in arterial blood $\left(\mathrm{PaO}_{2}\right)$, and $19 \%$ developed various degrees of hypoxemia ${ }^{8}$. The physiological effect of N95 respirators among healthcare professionals was investigated by Rebmann et al., who demonstrated a small but significant increase in $\mathrm{CO}_{2}$ levels among ten intensive care unit nurses who used N95 respirators for 12-hour shifts ${ }^{10}$. Although $\mathrm{CO}_{2}$ concentration differences were not statistically significant in our study, there was an upward trend after a 4-hour shift. A lack of power due to the small sample size may explain the variance between these findings and those of the present study.

The physiological impact of N95 respirator use during physical effort has been previously evaluated during exercise using a treadmill ${ }^{11,12}$ with findings supporting mild increases in $\mathrm{CO}_{2}$ levels but no impact on respiratory rate, tidal volume, or breathing pattern. In the current study, we did not demonstrate a change in HR or pulse oximetry, possibly implying the physiological effects in healthy individuals are small and unlikely to lead to any adverse consequences. However, the changes in $\mathrm{pH}, \mathrm{PvO}_{2}$, and $\mathrm{EtCO}_{2}$ suggest a degree of hypoventilation and/or $\mathrm{CO}_{2}$-rebreathing that may be provoked by wearing $\mathrm{N} 95$ respirators for prolonged, uninterrupted periods. The effect of these changes during longer shifts or where additional tape is used to seal the mask further and in those workers with pre-existing cardio-respiratory disease has not been defined. Several studies have suggested mechanistic links between chronic intermittent hypoxemia and increased production of reactive oxygen species, endothelial dysfunction, systemic inflammation, and pulmonary hypertension ${ }^{13,14}$, which may lead to longer-term consequences in susceptible individuals.

Strengths of this study include the use of N95 respirators by healthcare professionals in a typical setting of a 4-hour ED shift and the use of invasive blood gas assessment as well as non-invasive indices such as $\mathrm{EtCO}_{2}$ and pulse-oximetry for comparison. Limitations include the use of venous rather than arterial blood gas measurements to make it more comfortable for the study participants and provide an approximation to arterial values. Venous $\mathrm{pH}$ and $\mathrm{pCO}_{2}$ correlate well with arterial values (although they are not interchangeable) but are unsuitable for determining patient oxygenation ${ }^{15,16}$. The study also did not capture self-reported symptoms, so correlations with physiological changes could not be explored. Of course, a control group without N95 masks was not possible due to safety concerns. Future studies should include healthcare workers wearing these respirators for longer shifts, including those in 'Corona 
units' where additional precautions such as hoods and tape may increase the seal on the face. Also, the effect of prolonged use of these respirators in smokers and those with pre-existing cardiorespiratory disease or obesity is not known and is relevant as these PPE devices will be widely used for the foreseeable future in hospitals.

\section{Conclusion}

Using an N95 respirator for prolonged periods by healthcare professionals may provoke changes in gas exchange. The clinical significance of these changes in terms of symptoms or longer-term health status is unknown and needs to be determined.

\section{Abbreviations}

ED: emergency department

PvO2: partial pressure of oxygen tension in Mixed venous blood

PvCO2: partial pressure of Carbon Dioxide In Mixed Venous Blood

EtCO2: End tidal CO2

PPE: Personal protective equipment

HR: heart rate

IQR: interquartile range

SARS CoV 2: Severe acute respiratory syndrome coronavirus 2

\section{Declarations}

Ethics approval and consent to participate: This was a single-center prospective observational study approved by the Institutional Research Ethics Board. Signed informed consent was obtained from all Participants.

Consent for publication: the manuscript doesn't contain any individual person's data in any form.

Availability of data and material: The datasets generated during and/or analyzed during the current study are available from the corresponding author on reasonable request. 
Funding: The author(s) received no financial support for the research, authorship, and/or publication of this article.

Competing interests: The authors declare that they have no competing interests

Authors' contributions: LS carried out the conceptualization and the data curation. GBH

participated in the collection of the data and the recruitment of participants. SC helped in

writing and reviewing the draft. IBZ participated in the design and the review of the study.

Al participated in study design and coordination. LS participated in study design and

coordination. EH participated in the design of the study and performed the statistical

analysis. LL conceived of the study, and supervised its coordination.

All authors read and approved the final manuscript.

Acknowledgements: Not applicable

\section{References}

1. Luo C, Yao L, Zhang L, et al. Possible Transmission of Severe Acute Respiratory Syndrome Coronavirus 2 (SARS-CoV-2) in a Public Bath Center in Huai'an, Jiangsu Province, China. JAMA Netw Open. 2020;3(3):e204583.

2. Maclntyre CR, Chughtai AA, Rahman B, et al. The efficacy of medical masks and respirators against respiratory infection in healthcare workers. Influenza Other Respir Viruses. 2017;11(6):511-517.

3. Maclntyre CR, Wang Q, Rahman B, et al. Efficacy of face masks and respirators in preventing upper respiratory tract bacterial colonization and co-infection in hospital healthcare workers - authors' reply. Prev Med. 2014;65:154.

4. Smith JD, MacDougall CC, Johnstone J, Copes RA, Schwartz B, Garber GE. Effectiveness of N95 respirators versus surgical masks in protecting health care workers from acute respiratory infection: a systematic review and meta-analysis. CMAJ. 2016;188(8):567-574.

5. Ramirez-Moreno JM, Ceberino D, Gonzalez Plata A, et al. Mask-associated 'de novo' headache in healthcare workers during the COVID-19 pandemic. Occup Environ Med. 2020.

6. Hua W, Zuo Y, Wan R, et al. Short-term skin reactions following use of N95 respirators and medical masks. Contact Dermatitis. 2020;83(2):115-121.

7. Scheid JL, Lupien SP, Ford GS, West SL. Commentary: Physiological and Psychological Impact of Face Mask Usage during the COVID-19 Pandemic. Int J Environ Res Public Health. 2020;17(18).

8. Kao TW, Huang KC, Huang YL, Tsai TJ, Hsieh BS, Wu MS. The physiological impact of wearing an N95 mask during hemodialysis as a precaution against SARS in patients with end-stage renal 
disease. J Formos Med Assoc. 2004;103(8):624-628.

9. Hopkins SR, Dominelli PB, Davis CK, et al. Facemasks and the Cardiorespiratory Response to Physical Activity in Health and Disease. Ann Am Thorac Soc. 2020.

10. Rebmann T, Carrico R, Wang J. Physiologic and other effects and compliance with long-term respirator use among medical intensive care unit nurses. Am J Infect Control. 2013;41(12):12181223.

11. Epstein D, Korytny A, Isenberg Y, et al. Return to training in the COVID-19 era: The physiological effects of face masks during exercise. Scand J Med Sci Sports. 2021;31(1):70-75.

12. Roberge RJ, Coca A, Williams WJ, Powell JB, Palmiero AJ. Physiological impact of the N95 filtering facepiece respirator on healthcare workers. Respir Care. 2010;55(5):569-577.

13. Kimura H, Ota H, Kimura Y, Takasawa S. Effects of Intermittent Hypoxia on Pulmonary Vascular and Systemic Diseases. Int J Environ Res Public Health. 2019;16(17).

14. Zhou J, Bai W, Liu Q, Cui J, Zhang W. Intermittent Hypoxia Enhances THP-1 Monocyte Adhesion and Chemotaxis and Promotes M1 Macrophage Polarization via RAGE. Biomed Res Int. 2018;2018:1650456.

15. Tavakol K, Ghahramanpoori B, Fararouei M. Prediction of Arterial Blood pH and Partial Pressure of Carbon dioxide from Venous Blood Samples in Patients Receiving Mechanical Ventilation. J Med Signals Sens. 2013;3(3):180-184.

16. Byrne AL, Bennett M, Chatterji R, Symons R, Pace NL, Thomas PS. Peripheral venous and arterial blood gas analysis in adults: are they comparable? A systematic review and meta-analysis. Respirology. 2014;19(2):168-175.

\section{Figures}




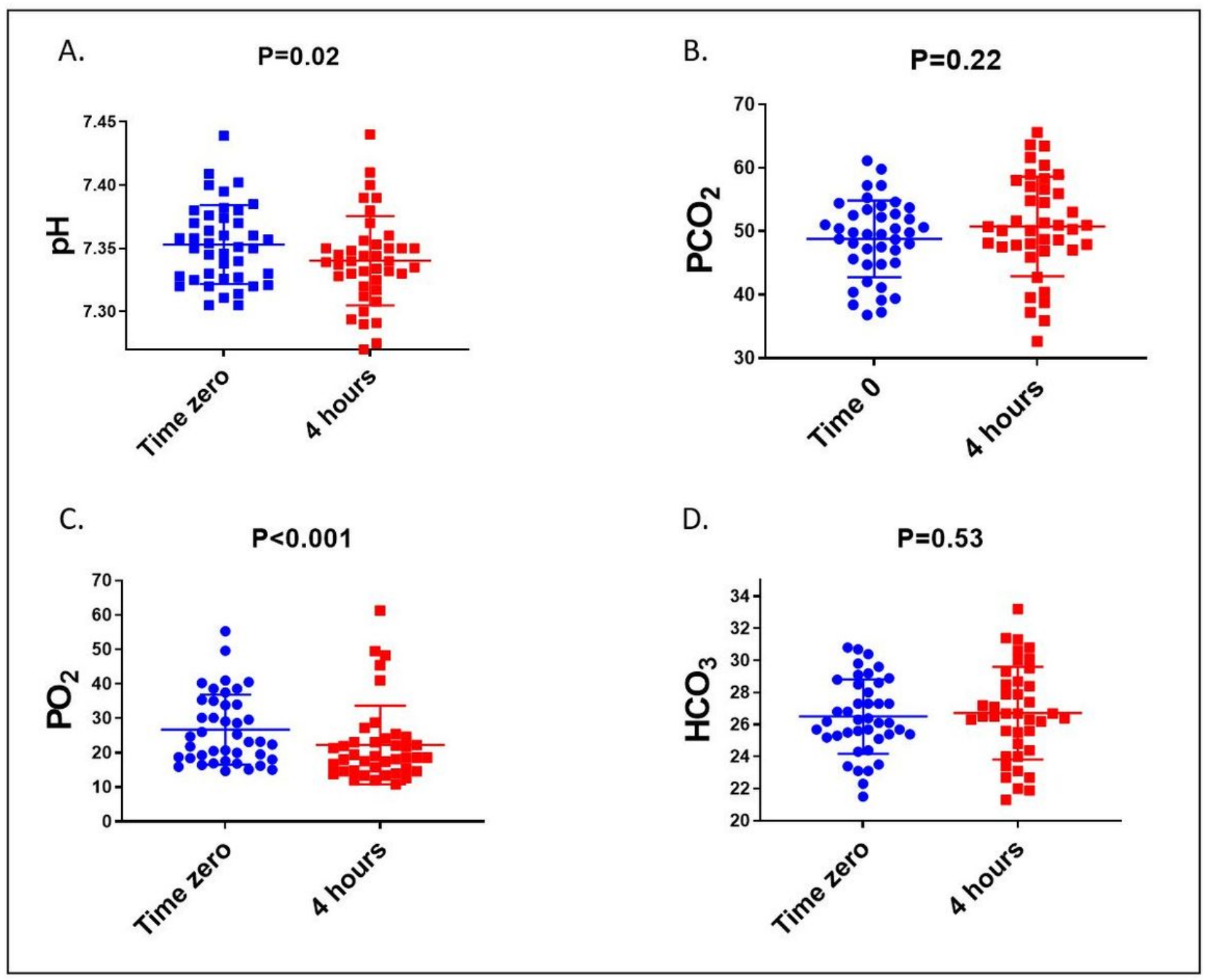

Figure 1

Effects of prolonged $\mathrm{N} 95$ respirator use on $\mathrm{pH}$ level (A); partial pressure of venous carbon dioxide (PCO2) (B); partial pressure of venous oxygen (PO2) (C); bicarbonate level (HCO3) (D). 